\title{
Towards the Recovery of By-Product Metals from Mine Wastes: An X-Ray Absorption Spectroscopy Study on the Binding State of Rhenium in Debris from a Centennial Iberian Pyrite Belt Mine
}

\author{
Maria-Ondina Figueiredo1,2*, Teresa Pereira da Silva², João Pedro Veiga1, \\ Daniel de Oliveira ${ }^{2}$, Maria João Batista ${ }^{2}$ \\ ${ }^{1}$ CENIMAT/I3N, Faculty of Sciences and Technology, New University of Lisbon, Campus da Caparica, Lisbon, Portugal \\ ${ }^{2}$ Unit of Mineral Resources and Geophysics, National Laboratory for Energy and Geology, Amadora, Portugal \\ Email: *ondina.figueiredo@Ineg.pt
}

Received 3 December 2013; revised 3 January 2014; accepted 20 January 2014

Copyright (C) 2014 by authors and Scientific Research Publishing Inc.

This work is licensed under the Creative Commons Attribution International License (CC BY).

http://creativecommons.org/licenses/by/4.0/

c) (i) Open Access

\section{Abstract}

Rhenium is a very scarce element, occurring in the Earth's crust mainly carried by molybdenite $\left(M_{2}\right)_{2}$. Due to a very low availability comparative to actual industrial demand, rhenium is nowadays one of the most expensive mineral commodities and an increased interest is focused on exploring residues resulting from a long-term mining, particularly of sulphide ore deposits. It is therefore noteworthy to assign the presence of rhenium (in a concentration up to $3 \mathrm{ppm}$ ) in the waste materials from the old sulphur factory at the abandoned mine of São Domingos (Iberian Pyrite Belt, Southeast Portugal), exploited since the Roman occupation of Iberia. Aiming at a potential sustainable recovery of rhenium as a by-product, $X$-ray near-edge absorption spectroscopy (XANES) was applied to clarify the Re-binding and mode of occurrence by comparing $\operatorname{Re} L_{3}$-edge XANES spectra obtained from mine waste samples (previously fully characterized by X-ray laboratory techniques) with similar spectra collected from Re-rich molybdenites $\left(M_{o_{1-x}} R_{x} S_{2}\right)$ and from Re-O model compounds configuring various valences and coordination environments of rhenium ions. Obtained results are commented, ruling out a possible Re-S binding and rather conforming with the binding of rhenium to oxygen in the analysed mine waste materials.

\section{Keywords}

Mine Waste Materials By-Products; Iberian Pyrite Belt; Rhenium; XANES; Re $L_{3}$-Edge

"Corresponding author.

How to cite this paper: Figueiredo, M.O., Silva, T.P., Veiga, J.P., de Oliveira, D. and Batista, M.J. (2014) Towards the Recovery of By-Product Metals from Mine Wastes: An X-Ray Absorption Spectroscopy Study on the Binding State of Rhenium in Debris from a Centennial Iberian Pyrite Belt Mine. Journal of Minerals and Materials Characterization and Engineering, 2, 135-143. http://dx.doi.org/10.4236/jmmce.2014.22018 


\section{Introduction}

The last naturally occurring chemical element to be discovered—rhenium—is highly valuable but very scarce, with an average concentration in the Earth's crust estimated to be lower than $1 \mathrm{ppb}$ [1].

Rhenium occurs in Nature mainly carried by molybdenite, $\mathrm{MoS}_{2}$ [2] and its presence is assumed to be related with the volatile transport of other refractory metals-Mo and W-by high temperature magmatic fluids [3]. This highly dispersed element has been assigned in granite pegmatites and quartz veins (e.g. in Japan [4]), but it occurs mainly in ores of porphyry copper-molybdenum deposits [5]-[8]. It has been extracted mainly as a byproduct of the copper mining industry and recovered in the refinement of molybdenum concentrates because the flue dusts collected by roasting these materials are enriched in the volatile molecular oxide $\operatorname{Re}_{2} \mathrm{O}_{7}$ [9], which is the usual source of the metal via conversion to $\left(\mathrm{NH}_{4}\right) \mathrm{ReO}_{4}$ and reduction by $\mathrm{H}_{2}$ at elevated temperatures. Indeed, rhenium volatilization during molybdenite roasting was recognized already forty years ago [10]. The largest world rhenium producer is Chile, followed by the United States, Kazakhstan — where it is found associated with copper minerals in sedimentary deposits-and Poland, which production has increased significantly in the last five years.

Rhenium is a typically chalcophile element, notably rare as a distinct mineral species. The first Re-mineral (rheniite, $\mathrm{ReS}_{2}$ ) was identified as a condensate in the fumaroles of Kudriavy volcano, Kurila Islands [11] and recently assigned in the Pagoni Rachi Mo-Cu-Te-Ag-Au prospect in northern Greece [7]. Another Re-mineral is tarkianite $(\mathrm{Cu}, \mathrm{Fe})(\mathrm{Re}, \mathrm{Mo})_{4} \mathrm{~S}_{8}$, a thiospinel phase associated with PGE-minerals at the Hitura mine, Finland [12].

This $5 d$ element, with a ground-state electronic configuration [Xe] $4 f^{14} 5 d^{5} 6 s^{2}$, is positioned in the Periodic Table along the column 7 following manganese (Mn, a $3 d$ element) and technetium (Tc, an element not found in Nature), but its overall behaviour is closer to molybdenum (Mo), a $4 d$ element from the previous column. The formal valence of rhenium covers a remarkably wide range, from -1 to +7 , and the prevalence of the latter high oxidation state has rendered rhenium technologically relevant in the production of catalysts [13].

Due to its unique properties-high melting point (3180 C, only exceeded by tungsten and by carbon in diamond), high density, high modulus of elasticity and electrical resistivity, low friction, no ductile-to-brittle transition and high resistance to creep-rhenium applications cover nowadays distinctive areas that range from the biological and nuclear fields to the electrical and aero-spatial industries, particularly for the production of nickel-based superalloys applied in jet engines [14]. Because of a very low availability comparative to demand, rhenium is at present one of the most expensive industrial commodities.

Considering the actual interest in exploring mining residues from already exhausted ore deposits, it became clear that finding rhenium in concentrations up to $3 \mathrm{ppm}$ in waste materials from the old sulphur factory at Achada do Gamo in the São Domingos abandoned pyrite mine [15] deserves a particular attention. Accordingly, an element-specific technique sensitive for a very low concentration-X-ray absorption near-edge spectroscopy (XANES) using synchrotron radiation—was applied to disclose the mode(s) of rhenium occurrence in those old mine wastes, having in view a possible future recovery of this scarce element as a by-product metal.

\subsection{Brief Note on the Exhausted Ore Deposit of São Domingos in the Iberian Pyrite Belt}

The São Domingos massive sulphide orebody is dominated by pyrite and located at the top of a Volcano Sedimentary Complex (VSC) sequence belonging to a giant volcanogenic massive sulphide deposit, the Iberian Pyrite Belt (IPB). This ore deposit extends from Portugal to Spain in the south of the Iberian Peninsula (Figure 1).

The weathering of the São Domingos deposit [16] [17] resulted in extensive gossan horizons that were intensely mined during the Roman occupation of Iberia, particularly in southern Lusitania, and fully exploited along the 19th century. The recovery of sulphur for the production of sulphuric acid-largely used in the chemical industry-remained significant until the fifties of the 20th century.

A first look to the availability of rhenium in the mining residues from the exploitation of Portuguese massive sulphide ore deposits through the EU-FP7 research project ProMine ${ }^{1}$ has disclosed the occurrence of rhenium in waste materials from São Domingos mine, sampled in a scraped profile at Achada do Gamo, close to the old sulphur factory.

${ }^{1}$ ProMine (nano-particle products from new mineral resources in Europe) research and technological development project co-funded by the European Union (FP7-NMP-2008-LARGE-2, 228559). 


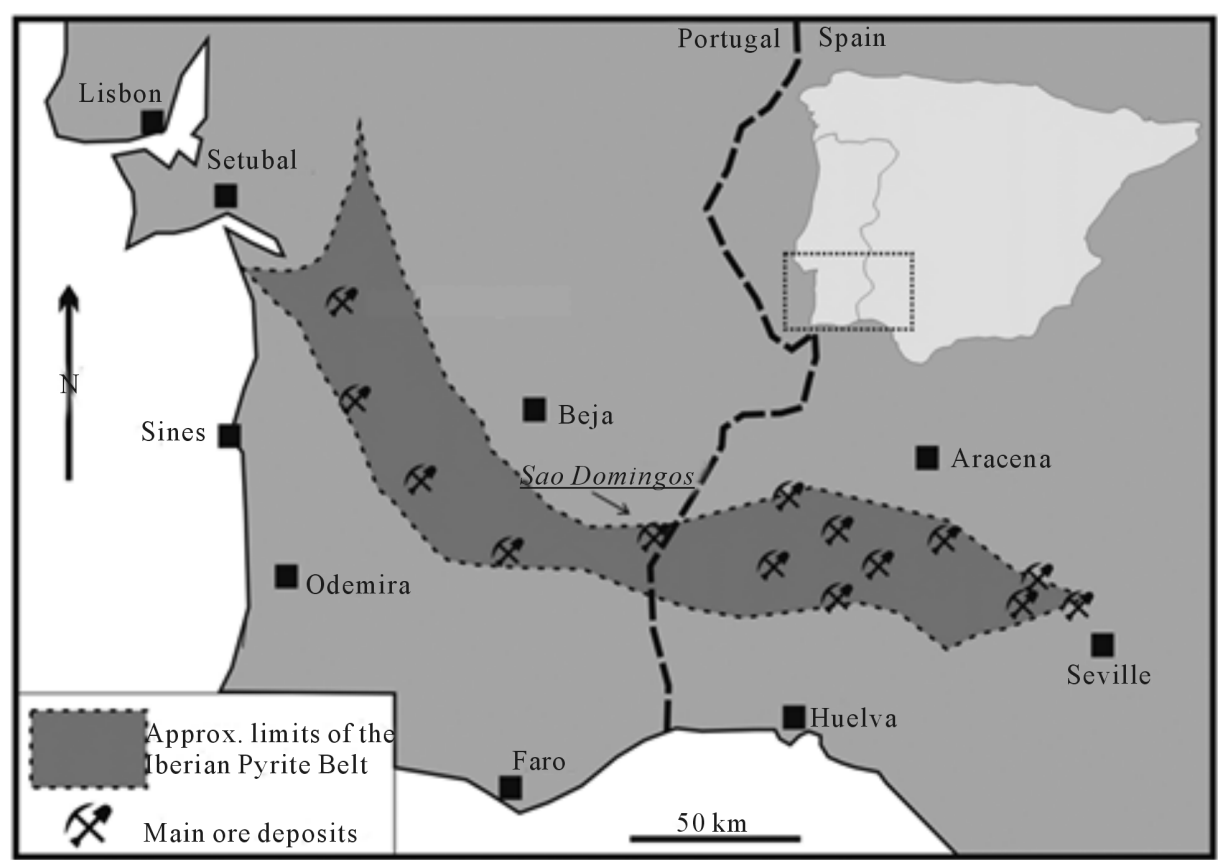

Figure 1. Location of the mining site of São Domingos in the Iberian Pyrite Belt.

Indeed, the wastes from previous exploitations of raw materials configure nowadays a potential economic value and focus the research on abandoned mine sites, having in view a potential sustainable recovery of valuable by-product metals from old mining residues_and this is actually the case of rhenium.

\subsection{Minerochemistry of Debris from Achada do Gamo at São Domingos Old Mine}

Achada do Gamo mining wastes deposited near the sulphur factory incorporate ashes from the sulphur production, along with milled pyrite and mineral debris from the copper-rich pyrite ores of the São Domingos ore deposit. Accordingly, they necessarily reflect the minerochemical differentiation related with the history of waste deposition and with the development of mining operations. The vertical variation in colour denoting chemical alterations endured after waste storage (Figure 2) has driven the selection of sampled materials for a previous minerochemical characterization.

X-ray diffraction (XRD) was applied to identify the component mineral phases by using a Philips powder diffractometer with Bragg-Brentano geometry, equipped with a large-anode copper tube and a curved graphite crystal monochromator.

The expected predominance of sulphate phases was confirmed by the mineralogical characterization (Table 1): anglesite, $\mathrm{PbSO}_{4}$, stemming from galena; jarosite, $\mathrm{KFe}_{3}(\mathrm{OH})_{6}\left(\mathrm{SO}_{4}\right)_{2}$, resulting from the weathering of iron sulphides; anhydrite, $\mathrm{CaSO}_{4}$, commonly associated with these sulphides and altered by hydration to form gypsum, $\mathrm{CaSO}_{4} \cdot 2 \mathrm{H}_{2} \mathrm{O}$.

An exploratory analysis of a wide range of elements performed on the sample profile of milled pyrite ore plus mining waste materials by an internationally certified laboratory [15] revealed that rhenium is present at concentrations significantly higher than its level at the earth's crust (Table 2). According to these analytical data, possible correlation(s) with other elemental contents could be conjectured-e.g., with selenium. To allow for an easy correlation with the mineralogical constitution of studied mine waste samples, the elemental concentrations obtained for some major elements are also listed.

X-ray fluorescence (XRF) spectrometry using a Philips PW1400 automated wavelength dispersive spectrometer (WDS) equipped with a rhodium tube and adequate analysing crystals was applied to identify the elements (major and minor chemical components) present in the mine wastes.

The analysing XRF lines of these elements were carefully selected to attain a comparative estimation of their relative proportions as shown in Figure 3; however, the detection of rhenium by this qualitative methodology is hindered by the presence of zinc due to the severe interference of $\mathrm{Zn} K \alpha$ line upon the diagnostic Re $L \alpha_{1,2}$ lines. 


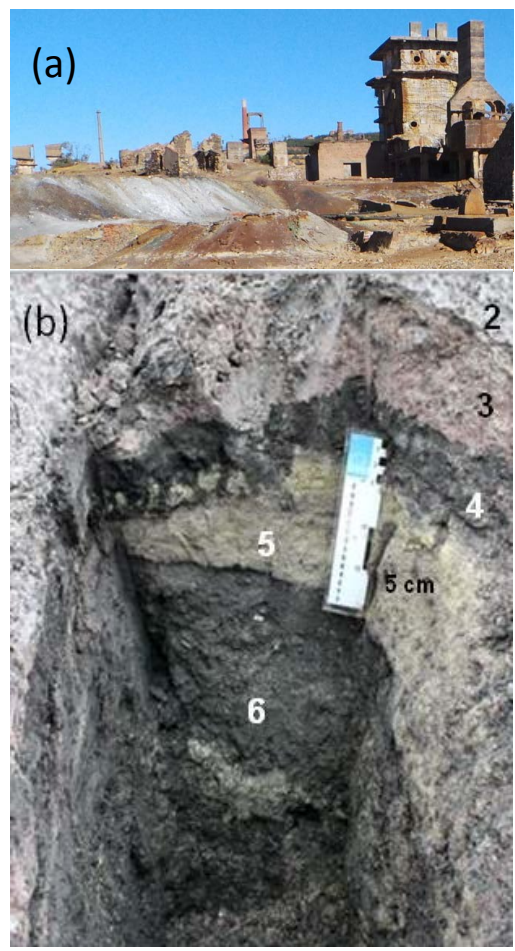

Figure 2. (a) Actual view of the sulphur factory area at Achada do Gamo, São Domingos old mine; (b) Profile of studied samples—-milled pyrite ore plus mining waste materials-collected at Achada do Gamo.

Table 1. XRD mineralogical characterization of mine waste materials from Achada do Gamo.

\begin{tabular}{ccccc}
\hline Sample & Description & & \multicolumn{2}{c}{ Phases identified (JCPDF card quoted bellow) } \\
\hline Ref. Nr. & & Main & Minor & Vestigial \\
\hline $\mathbf{2}$ & Light-grey layer & Anglesite & & Hematite \\
$\mathbf{3}$ & Faintly-rose layer & Anglesite & & Jarosite + Hematite \\
$\mathbf{4}$ & Grey layer & Anglesite & Gypsum & Jarosite \\
$\mathbf{5}$ & Yellowish layer & Jarosite & Anglesite + Feldspar & Anhydrite + Anatase \\
$\mathbf{6}$ & Dark grey layer & Anglesite & Jarosite & Anhydrite + Coquimbite \\
\hline
\end{tabular}

Anatase, $\mathrm{TiO}_{2}$ (4-477); Anglesite, $\mathrm{PbSO}_{4}$ (5-577); Anhydrite, $\mathrm{CaSO}_{4}$ (6-226); Coquimbite, $\mathrm{Fe}_{2}\left(\mathrm{SO}_{4}\right)_{3} \cdot 9 \mathrm{H}_{2} \mathrm{O}$ (6-40); Feldspar, (K, $\mathrm{Na} \mathrm{AlSi}_{3} \mathrm{O}_{8}(9-462)$; Gypsum, $\mathrm{CaSO}_{4} \cdot 2 \mathrm{H}_{2} \mathrm{O}(6-46)$; Hematite, $\alpha-\mathrm{Fe}_{2} \mathrm{O}_{3}(13-524)$; Jarosite, $\mathrm{KFe}_{3}(\mathrm{OH})_{6}\left(\mathrm{SO}_{4}\right)_{2}(22-827)$.

Table 2. Distribution of several elements in the sampled mine waste profile (ACTLABS data [15]).

\begin{tabular}{ccccccccc}
\hline Sample & Re $(\mathrm{ppm})$ & $\mathrm{Se}(\mathrm{ppm})$ & $\mathrm{Ca}(\%)$ & $\mathrm{Fe}(\%)$ & $\mathrm{K}(\%)$ & $\mathrm{Al}(\%)$ & $\mathrm{Ti}(\%)$ \\
\hline 2 & 2.12 & 564 & 0.11 & 0.84 & 0.20 & 0.36 & 0.15 \\
$\mathbf{3}$ & $\mathbf{3 . 0 6}$ & $\mathbf{9 3 7}$ & 1.66 & 2.81 & 0.19 & 0.43 & 0.19 \\
$\mathbf{4}$ & $\mathbf{3 . 4 0}$ & $\mathbf{7 3 8}$ & 2.64 & 2.76 & 0.55 & 0.65 & 0.14 \\
$\mathbf{5}$ & $\mathbf{2 . 6 5}$ & $\mathbf{5 0 7}$ & 2.52 & 9.45 & 0.76 & 1.03 & 0.23 \\
6 & 1.34 & 212 & 3.02 & 4.98 & 0.78 & 0.56 & 0.05 \\
\hline
\end{tabular}




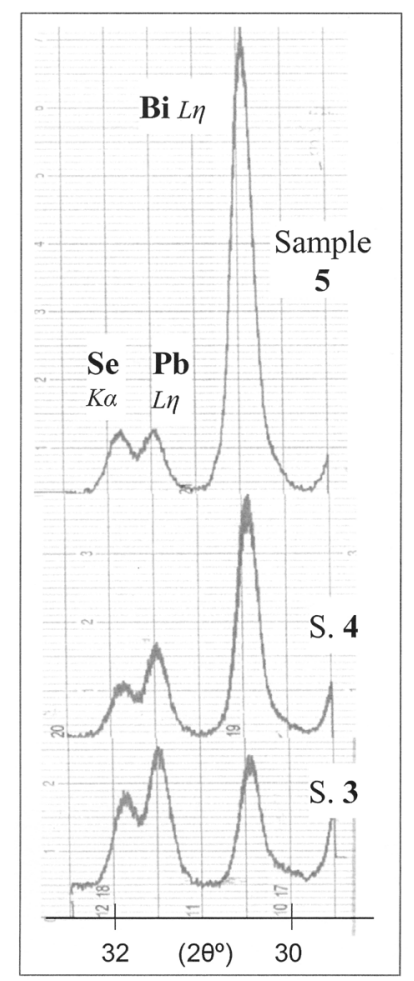

Figure 3. XRF-WDS spectra collected from waste samples 3 - 5 in the $2 \theta^{\circ}$ angular region abridging the $\mathrm{X}$-ray emission lines used to compare the relative contents of selenium, lead and bismuth.

In view of the bulk chemical and mineralogical data, the sample displaying the highest Re-content (sample 4) was selected for a first X-ray absorption spectroscopy study, focused on assessing the binding state of this scarce metal in the debris from São Domingos old mine and desirably allowing enlightening the mode of occurrence of this valuable element in the original sulphide ore deposit for which the occurrence of molybdenite has not been reported.

\section{Experimental}

\subsection{Studied Materials}

A fragment of a molybdenite museum specimen from Aldfield, Quebec/Canada—where this mineral occurs in a pyroxene-rock associated with pyrite and pyrrhotite [18] — was studied to collect the XANES standard spectrum of rhenium hosted by molybdenite, $\mathrm{Mo}_{1-\mathrm{x}} \mathrm{Re}_{\mathrm{x}} \mathrm{S}_{2}$-that is, Re ions with assumed formal valence 4+ and supposedly prismatic coordination by sulphide anions.

Commercial products (99.9\% purity) were used as model Re-O compounds (previously checked by XRD) to configure various coordination environments and formal valences of the metal ions [19]: $\mathrm{ReO}_{3}$, a perovskitetype oxide with $\mathrm{Re}^{6+}$ ions assuming a regular octahedral coordination and which electronic structure has been studied for long [20]; $\mathrm{Re}_{2} \mathrm{O}_{7}$, a molecular compound that incorporates $\mathrm{Re}^{7+}$ ions in both octahedral and tetrahedral coordinations by oxygen anions [9]; and potassium perrhenate, $\mathrm{KReO}_{4}$, an ionic compound with $\mathrm{Re}^{7+}$ ions exclusively in tetrahedral coordination [21].

\subsection{Methods and Techniques}

The X-ray absorption experiment at Re $L_{3}$-edge was carried out at the European Synchrotron Radiation Facility 
(ESRF, in Grenoble/France) using the instrumental set-up of beam line BM-23. XANES spectra were collected using a Si (111) double crystal monochromator with detuning for harmonic rejection. An energy resolution of about $0.8 \mathrm{eV}$ was in this way assured at the Re $L_{3}$ absorption edge of the metal $(10.535 \mathrm{keV})$.

The small fragment of Aldfield molybdenite and the powdered mining waste materials were enclosed between two ultra-pure kapton adhesive tapes and directly irradiated. The out-coming fluorescence yield was detected using a 13-element Ge-detector. The model compounds were slightly grinded to prepare pressed pellets after mixing with boron nitride in a proportion adequate to optimize the absorption jump, while minimizing the total absorption; in this way, the display of edge features from the XANES spectra collected in transmission mode was improved. The energy calibration of these spectra was carried out by irradiating a foil of rhenium metal.

\section{Results and Discussion}

X-ray absorption near-edge spectra are sensitive both to the electronic structure of the absorber and to its geometrical environment by coordinating atoms. Symmetrical aspects are reflected as well in the absorption spectra, particularly the absence of a symmetry centre in the coordination polyhedra—intrinsically in tetrahedra, but also in distorted octahedra.

Re $L_{3}$-edge XANES spectra collected from the model compounds selected for the present study (Figure 4) match the spectral data published on rhenium oxide compounds, starting with works dated from the seventies [22] to the nineties [19] [20] [23], up to a recent publication [24].

The intense self-absorption peak at the absorption edge—the so-called "white line" [25]—has an amplitude that depends essentially from the occupation of the $5 d$ electron level of rhenium atoms [24]. Accordingly, its energy is sensitive to the formal valence of rhenium ions: $\mathrm{Re}^{6+}$ in $\mathrm{ReO}_{3}(10,544 \mathrm{eV})$ and $\mathrm{Re}^{7+}$ in the other two model compounds (10542.5 eV).

Simultaneously, the XANES region following the absorption edge displays distinct features (Figure 4). The energies associated to these details reflect differences in coordination geometries: octahedral $\mathrm{Re}^{6+}$ in $\mathrm{ReO}_{3}$ [26] and tetrahedral $\mathrm{Re}^{7+}$ in both $\mathrm{KReO}_{4}$ [21] and $\mathrm{Re}_{2} \mathrm{O}_{7}$. Significant as well is the energy corresponding to the absorption rise observed at about $60 \mathrm{eV}$ above the edge in the XANES spectra of Re-rich molybdenite (Figure 5). Similar absorption increments are noticed at higher energy for both the molecular compound $\mathrm{Re}_{2} \mathrm{O}_{7}$ and the studied mine waste sample.

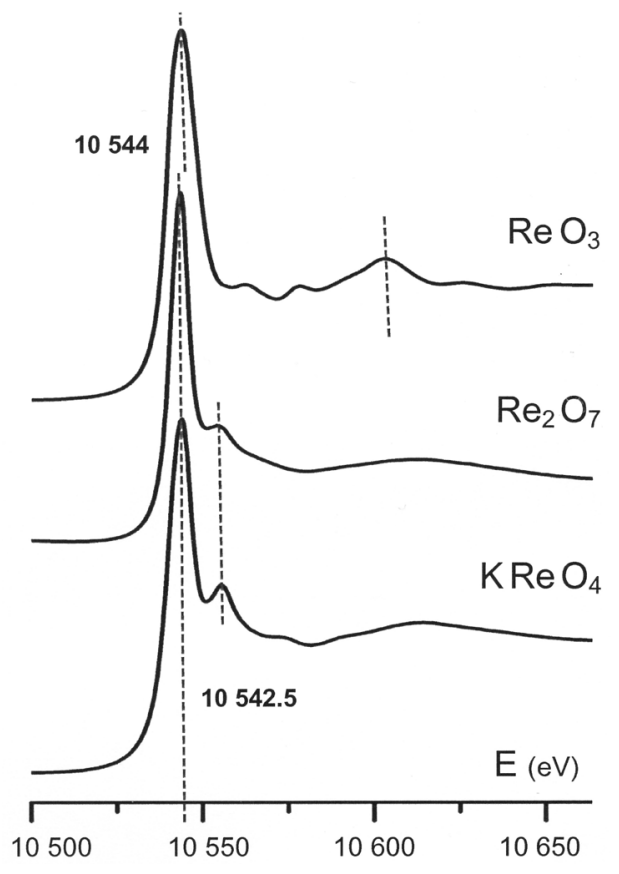

Figure 4. Re $L_{3}$-edge XANES spectra obtained from the studied model compounds. 
The Re $L_{3}$-edge XANES spectra obtained from this waste material has a very poor resolution when compared with the high quality of the spectra collected from molybdenite and from the model compounds. Even so, considering the very low Re-contents of the mine debris (Table 2) and the complex chemical matrix of these materials, it is worth emphasizing that the spectroscopic capability of collecting those XANES spectra configures a quite remarkable experimental accomplishment.

\section{Conclusions}

Present spectroscopic data emphasize the sensitivity of the "white line" energy in Re $L_{3}$-edge XANES spectra to the formal valence and to the binding of the absorbing element: the spectrum collected from Aldfield molybdenite reproduced in Figure 5- $\mathrm{Mo}_{1-\mathrm{x}} \mathrm{Re}_{\mathrm{x}} \mathrm{S}_{2}$ [27] —reflects the lower valence of rhenium ions (4+) and their binding to sulphur through a lower energy of the "white line" $(10,540 \mathrm{eV})$; comparatively, the higher valences assumed by rhenium ions in the model oxide compounds-6+ in $\mathrm{ReO}_{3}$ and 7+ in $\mathrm{Re}_{2} \mathrm{O}_{7}$-bring about slightly higher energies, respectively 10,544 eV and $10542.5 \mathrm{eV}$ (Figure 4).

Spectroscopic results so far obtained discard a possible Re-S binding with formal valence 4+ of the rhenium ions and allow assuming that this scarce metal is rather binded to oxygen under a higher valence state in the analysed materials. Although rhenium concentrations are very low in the studied mine wastes, actual results encourage a future re-appraisal of the former Re-carrier mineral(s) in the original copper-rich pyrite ores exploited at the São Domingos mine, since the occurrence of molybdenite was never formerly reported for the Iberian Pyrite Belt deposit there exploited. Not less important is the significant positive implication that these results may have upon a sustainable future recovery of critical raw materials from mine wastes [28].

The success of the present X-ray absorption spectroscopy approach to the binding state of rhenium in old mining wastes encourages further developments, particularly by looking at coexisting elements and collecting $\mathrm{X}$-ray diffraction spectra at the irradiated points in a forthcoming synchrotron radiation experiment focused on other carefully selected Re-containing old mining debris.

\section{Acknowledgements}

Work developed within the project MinReMol (Ref. EXPL/AAG-REC/0978/2012), financed by FEDER Funds

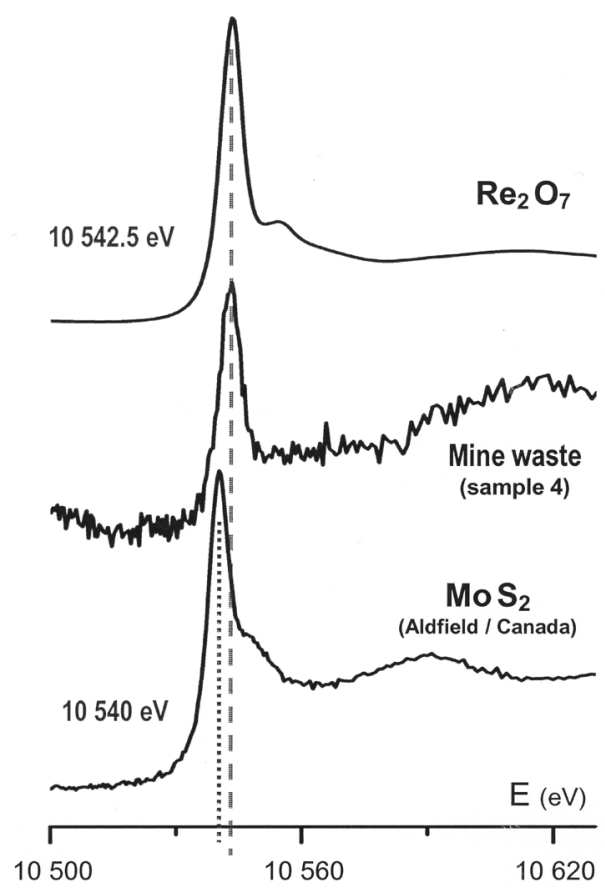

Figure 5. Re $L_{3}$-edge XANES spectra collected from representative studied materials. 
through the Operational Program on Competitive Factors (COMPETE: FCOMP-01-0124-FEDER-027516) and by national funds through the Portuguese Foundation for Science and Technology (FCT-MCTES).

EU financial support to perform the X-ray absorption experiment CH-3421 at the ESRF is acknowledged. Special thanks are due to the beamline technical staff.

Authors affiliated to CENIMAT/I3N acknowledge the support of FCT-MCTES through the Strategic Project LA25-2011-2012 (ref. PEst-C/CTM/LA0025/2011).

\section{References}

[1] Noddack, I. and Noddack, W. (1931) Die Geochemie des Rheniums. Zeitshrift für Physikalische Chemie, A154, 207244.

[2] Fleischer, M. (1959) The Geochemistry of Rhenium, with Special Reference to Its Occurrence in Molybdenite. Economic Geology, 54, 1406-1413. http://dx.doi.org/10.2113/gsecongeo.54.8.1406

[3] Bernard, A., Symons, R.B. and Rose, W.I. (1990) Volatile Transport and Deposition of Mo, W and Re in High Temperature Magmatic Fluids. Applied Geochemistry, 5, 317-326. http://dx.doi.org/10.1016/0883-2927(90)90007-R

[4] Ishihara, S. (1988) Rhenium Contents of Molybdenites in Granitoid-Series Rocks in Japan. Economic Geology, 83, 1047-1051. http://dx.doi.org/10.2113/gsecongeo.83.5.1047

[5] Berzina, A.N., Sotnikov, V.I., Economou-Eliopoulos, M. and Eliopoulos, D.G. (2005) Distribution of Re in Molybdenite from Porphyry Cu-Mo and Mo-Cu Deposits of Russia (Siberia) and Mongolia. Ore Geology Reviews, 26, 91-113. http://dx.doi.org/10.1016/j.oregeorev.2004.12.002

[6] Voudouris, P.C., Melfos, V., Spry, P.G., Bindi, L., Kartal, T., Arikas, K., Moritz, R. and Ortelli, M. (2009) RheniumRich Molybdenite and Rheniite in the Pagoni Rachi Mo-Cu-Te-Ag-Au Prospect, Northern Greece: Implications for the Re Geochemistry of Porphyry-Style Cu-Mo and Mo Mineralization. Canadian Mineralogist, 47, 1013-1036. http://dx.doi.org/10.3749/canmin.47.5.1013

[7] Brown, M., Lazo, F., Carter, P., Goss, B. and Kirwin, D. (2010) The Geology and Discovery of Merlin Mo-Re Zone of Mount Dore Deposit, Mount Isa Inlier, NW Queensland, Australia. SGA News, 27, 9-15.

[8] Aminzadeh, B., Shahabpour, J. and Maghami, M. (2011) Variation of Rhenium Contents in Molybdenites from the Sar Cheshmeh Porphyry Cu-Mo Deposits in Iran. Resource Geology, 61, 290-295. http://dx.doi.org/10.1111/j.1751-3928.2011.00165.x

[9] Krebs, B., Müller, H. and Beyer, H. (1968) A New Type of Oxide Structure: The Crystal Structure of Rhenium (VII) Oxide. Chemical Communications (London), 61, 263-264.

[10] Amman, P.R. and Loose, T.A. (1972) Rhenium Volatilization during Molybdenite Roasting. Metallurgical Transactions, 3, 1020-1021. http://dx.doi.org/10.1007/BF02647690

[11] Korzhinsky, M.A., Tkachenko, S.I., Shmulovich, K.I., Taran, Y.A. and Steinberg, G.S. (1994) Discovery of a Pure Rhenium Mineral at Kudriavy Volcano. Nature, 369, 51-52. http://dx.doi.org/10.1038/369051a0

[12] Kojonen, K.K., Roberts, A.C., Isomäki, O.-P., Knauf, V.F., Johanson, I. and Pakkanen, L. (2004) Tarkianite, (Cu,Fe) (Re,Mo) ${ }_{4} \mathrm{~S}_{8}$, a New Mineral Species from the Hitura Mine, Nivala, Finland. Canadian Mineralogist, 42, 539-544. http://dx.doi.org/10.2113/gscanmin.42.2.539

[13] Bare, S.R., Kelly, S.D., Vila, F.D., Boldingh, E., Karapetrova, E., Kas, J., Mickelson, G.E., Modika, F.S., Yang, N. and Rehr, J.J. (2011) Experimental (XAS, STEM, TPR and XPS) and Theoretical (DFT) Characterization of Supported Rhenium Catalysts. Journal of Physical Chemistry C, 115, 5740-5755. http://dx.doi.org/10.1021/jp1105218

[14] Naor, A., Eliaz, N., Gileadi, E. and Taylor, S.R. (2010) Properties and Applications of Rhenium and Its Alloys. AMMTIAC Quarterly, 5, 11-15.

[15] Batista, M.J., Matos, J.X., Figueiredo, M.O., de Oliveira, D., Silva, T.P., Santana, H. and Quental, L. (2011) Fingerprints for Mining Products and Wastes from the S. Domingos, Aljustrel and Neves Corvo Mines-A Sustainable Perspective. Proceedings of the VIII Iberian Congress of Geochemistry, Castelo-Branco, 6. http://repositorio.lneg.pt/handle/10400.9/1450

[16] Webb, J. (1958) Observations on the Geology and Origin of the São Domingos Pyrite Deposit, Portugal. Comunicações dos Serviços Geológicos de Portugal, 42, 119-143.

[17] Matos, J.X., Pereira, Z., Oliveira, V. and Oliveira, J.T. (2006) The Geological Setting of the São Domingos Pyrite Orebody, Iberian Pyrite Belt. Proceedings of the VII National Geology Congress, Estremoz, 283-286.

[18] Walker, T.L. (1911) Report on the Molybdenum Ores of Canada. Government Printing Bureau, Department of Mines, Ottawa, No. 93, 30-31. http://www.archive.org/details/reportonmolybden00walkrich

[19] Witschek, G., Fröba, M., Füess, H. and Metz, W. (1994) XAS and XRD Studies of Rhenium-Oxygen Compounds. Fresenius Journal of Analytical Chemistry, 349, 230-231. http://dx.doi.org/10.1007/BF00323289 
[20] Corá, F., Stachiotti, M.G., Catlow, C.R.A. and Rodriguez, C.O. (1997) Transition Metal Oxide Chemistry: Electronic Structure Study of $\mathrm{WO}_{3}, \mathrm{ReO}_{3}$ and $\mathrm{NaWO}_{3}$. Journal of Physical Chemistry B, 101, 3945-3952. http://dx.doi.org/10.1021/jp963724z

[21] Morrow, J.C. (1963) The Crystal Structure of $\mathrm{KReO}_{4}$. Acta Crystallographica, 13, 443. http://dx.doi.org/10.1107/S0365110X60001035

[22] Mande, C., Pendharkar, A.V. and Chakravorti, M.C. (1972) The Shapes of $L_{3}$ Absorption Discontinuity of Rhenium in Compounds. Proceedings of the Indian Academy of Sciences, Section A, 75, 209-216. http://www.ias.ac.in/j_archive/proca/75/5/209-216/viewpage.html

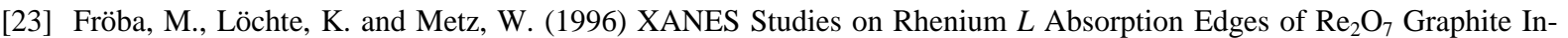
tercalation Compounds and Other Rhenium-Oxygen Compounds. Journal of Physical Chemistry of Solids, 57, 635641. http://www.sciencedirect.com/science/article/pii/0022369795002421

[24] Tougerti, A., Crystol, S., Briois, V., La Fontaine, C., Villain, F. and Joly, Y. (1996) XANES Study of Rhenium Oxide Compounds at the $L_{1}$ and $L_{3}$ Absorption Edges. Physical Review B, 57, 635-641. http://dx.doi.org/10.1103/PhysRevB.85.125136

[25] Cauchois, Y. and Mott, N.F. (1949) The Interpretation of X-Ray Absorption Spectra of Solids. Philosophical Magazine, 40, 1260-1269.

[26] Kuzmin, A., Purans, J., Benfatto, M. and Natoli, C.R. (1993) X-Ray Absorption Study of Rhenium $L_{1}$ and $L_{3}$ Edges in $\mathrm{ReO}_{3}$ : A Multiple Scattering Approach. Physical Review B, 47, 2480-2486. http://dx.doi.org/10.1103/PhysRevB.47.2480

[27] Silva, T.P., Figueiredo, M.O., de Oliveira, D.P., Veiga, J.P. and Batista, M.J. (2013) Molybdenite as a Rhenium Carrier: First Results of a Spectroscopic Approach Using Synchrotron Radiation. Journal of Minerals and Materials Characterization and Engineering, 1, 207-211. http://dx.doi.org/10.4236/jmmce.2013.15032

[28] Figueiredo, M.O., Silva, T.P., Batista, M.J., Veiga, J.P. and de Oliveira, D.P. (2013) Opportunities for Recovering Critical Raw Materials from Mine Wastes: The Type-Case of Rhenium in Residues from the Exploitation of Old Portuguese Mines. WASTES: Solutions, Treatments and Opportunities, $2^{\text {nd }}$ International Conference, Braga/Portugal, September 2013, Poster, Book of Abstracts, 163-164. 